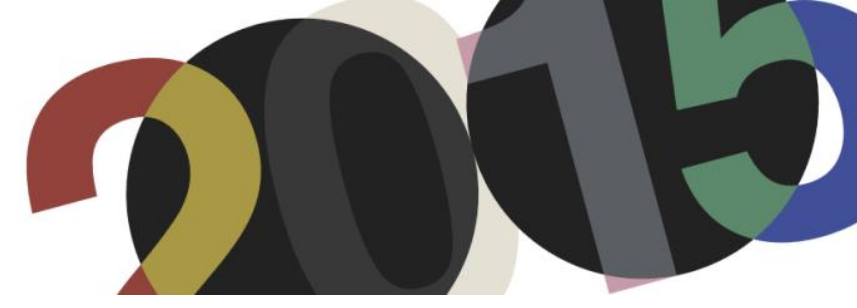

DOI: http://dx.doi.org/10.4995/LC2015.2015.837

\title{
Elogio del cuadrado: cuadrícula, cuadro, cuatro, cubo
}

\author{
A. Martínez-Medina \\ Área de Composición Arquitectónica. Dpto. de Expresión Gráfica y Cartografía. Universidad de Alicante
}

\begin{abstract}
Resumen: Un recorrido por la producción de Le Corbusier evidencia la insistente presencia del cuadrado como base de las composiciones en diversos campos (urbanismo, arquitectura, pintura, mobiliario...) y en diferentes formatos (en planta, alzado y sección, o como marco, módulo y cuadrícula). La presente comunicación realiza un análisis formal (gráfico y simbólico) de sus proyectos y obras, rastreando los modos en que se utiliza el cuadrado permaneciendo en el tiempo como una constante recurrente. Para ello se recorren cuatro áreas temáticas que descienden en escala y en dimensiones: 1) capitolios, 2) museos, 3) pabellones y 4) casas, estudiando una serie de ejemplos en cada área a partir de los planos de la Fundación Le Corbusier, generando discursos que reconstruyen un hilo del tiempo en la evolución de los procesos compositivos. De este modo, se desgrana el empleo del cuadrado, en correspondencia con las áreas de estudio, como: $1^{\circ}$ ) perímetro de la plaza pública donde insertar las arquitecturas representativas, $2^{\circ}$ ) marco o caja-fuerte donde encerrar los tesoros artísticos (o sagrados), $3^{\circ}$ ) volumen cúbico abierto y desmontable y $4^{\circ}$ ) caja definida por la retícula de la estructura. El cuadrado es siempre un medio y no un fin. Persiste un intento de sugerir algunos de los orígenes en su formación clasicista, sus viajes y sus pinturas.
\end{abstract}

\begin{abstract}
A tour through the production of Le Corbusier shows the insistent presence of the square as a basis of compositions in various fields (urban planning, architecture, painting, furniture...) and in different formats (in floor, elevation and profile, or as a theme, module and grid). This communication makes a formal analysis (graphic and symbolic) of its projects and works tracing the different ways to use the square that remains as a recurring constant. We can do it through four thematic areas descending in scale and dimensions: 1) capitols, 2) museums, 3) pavilions and 4) houses, studying a series of examples in each area based on the drawings of the Foundation Le Corbusier, generating speeches that reconstruct a thread of the time in the evolution of the compositional process. In correspondence with the four themes of study, we can discovery the employment of the square as different instruments. First: the square as the perimeter of the public space where to insert the representative architectures. Second: as a frame or safety deposit box where to enclose treasures artistic (or Holy). Third: as a cubic volume open and detachable. Fourth: as box defined by the grid of the structure. The square is always a means and not an end. In addition, there is an attempt to suggest some of the origins in his classic formation, his travels and his paintings.
\end{abstract}

Palabras clave: Le Corbusier, composición, cuadrícula, cuadrado, cuadro, cubo.

Keywords: Le Corbusier, composition, reticle, square, frame, cube.

\section{El cuadrado como composición (introducción)}

Un rápido repaso visual a toda la producción arquitectónica de Le Corbusier (en un principio: Charles-Édouard Jeanneret, 1887-1965) manifiesta la constante presencia de cuadrados que persisten a lo largo del tiempo en muy diversos formatos; la nitidez y rotundidad de esta geometría se vuelve más evidente en los planos y en los volúmenes de su última década. La permanencia de este tema formal en los distintos frentes de trabajo del maestro suizo revela, cuando menos, su apego y confianza en esta forma elemental, al margen de la escala del proyecto o de la materialidad de la obra, la cual sí presenta dos etapas, antes y después de la II Guerra Mundial (IIGM): la estética pulcra del objeto industrial (hecho a máquina) frente a la estética basta del objeto artesanal (hecho a mano). 
A los volúmenes ligeros, pero frágiles, que responden a los cinco principios para una Nueva Arquitectura (1926), le suceden sólidos graves que, en su masa de hormigón visto, se aproximan a los resistentes búnkeres que Paul Virilio veía como arqueología (1958), ruinas de la primera arquitectura moderna del siglo XX. Aunque pudiera especularse con que se trata de dos concepciones distantes de arquitectura, en realidad, ambas etapas responden a una única trayectoria de pensamiento que se sustenta sobre una misma base geométrica que sirve de entramado a casi todas sus obras. De hecho, el cuadrado (el medio y el doble) está presente en todas sus creaciones, sean estas de urbanismo, arquitectura, pintura, exposiciones, diseño de mobiliario o edición de libros, presentándose en diferentes formatos: en planta, alzado y sección o como marco límite, módulo ordenador y cuadrícula base. El propio Le Corbusier, antes de la IIGM, afirmó y evidenció en varias ocasiones su apoyo en los trazados reguladores de ascendencia clasicista (razón y sección áureas) así como, tras la IIGM, razonó la conveniencia del empleo de 'el modulor' elaborado por él mismo; el primero es un sistema de proporciones y el segundo es un sistema de medidas adaptado a la escala humana: ambos son herramientas que derivan de un cuadrado inicial ¿Qué tienen en común la capilla para el Hospital de Venecia, la fachada del Secretariado, la Unité de FirminyVert, el museo de Chandigarh, la sede de los Hiladores, la estructura de las manufacturas de Sant-Dié, los estudios en Cap Martin, el plan de Buenos Aires, las viviendas en Pessac o la casa Citrohan? Entre otras cuestiones, suponen un elogio del cuadrado, bien como inicio en la génesis del proyecto, bien como medio en el diseño, nunca como un fin en sí.

Para descubrir las recurrentes manifestaciones del cuadrado se ha optado por un análisis formal y gráfico de una amplia cantidad de proyectos cuyos planos se recogen en una publicación de 16 volúmenes de la Fundación Le Corbusier ${ }^{1}$. Se ha procedido a escalarlos y medirlos, a cuantificar pórticos, distancias, módulos, proporciones, ejes y diagonales, detectando la presencia y el uso de la figura protagonista. Los resultados de este análisis se han agrupado en cuatro áreas que descienden en escala y en dimensiones: capitolios, museos, pabellones y casas. Dentro de cada línea investigada se genera un discurso que reconstruye un hilo del tiempo en la evolución de los mecanismos compositivos aportando, en algunos casos, ciertas interpretaciones simbólicas. En correspondencia con estos cuatro campos, se desgrana el empleo del cuadrado en sus diferentes capacidades, en tanto que instrumento de orden y de significado. El discurrir cronológico también lo es hacia atrás en un intento de sugerir sus inicios en su formación clasicista, en sus viajes y en sus pinturas ${ }^{2}$. Puede que, para el maestro, todo partiese de un cuadrado patrón — sin escala - como motor de percepción y como garantía de orden, armonía y belleza. Con todo, nos interesa más el proceso evolutivo y cómo los temas (forma y metáfora) pasan de un lugar a otro urdiendo un tapiz de relaciones, aunque la realidad sea siempre más compleja que la aparente sencillez que aquí se expone.

\section{Temas de exploración: capitolios, museos, pabellones y casas (metodología y desarrollo)}

Intentaremos ser sintéticos al ofrecer una visión de la vasta y panorámica obra de Le Corbusier incidiendo en cuatro temas: capitolios (plazas encuadradas), museos de arte (boîte à miracles), pabellones de exposición (cubos desmontables) y casas (cuadradas y cúbicas), que se ordenan por escalas: de la mayor extensión (ciudad, ámbito público) a la menor dimensión (viviendas, ámbito privado).

\footnotetext{
${ }^{1}$ Para la cronología de los proyectos del presente texto, se toman las fechas de: Fondation Le Corbusier. Le Corbusier Plans, 1905-1965. (16 vols.). Paris: Echelle-1, 2005; la mayoría de planos que acompañan al presente proceden de esta fuente. El tratamiento digital de los planos y la composición de las imágenes ha sido realizada por David Gil Delgado.

${ }^{2}$ Calatrava, J. "Una visión del mundo. Le Corbusier: The Art of Postcards". Madrid: Arquitectura Viva, №170, 2015; pp: 4851. Esta exposición insiste en la estrecha relación figurativa entre las obras de LC, sus viajes y las postales.
} 


\subsection{Capitolios encuadrados: marcos llenos y vacíos}

Le Corbusier tuvo la oportunidad de hacer una ciudad de nueva planta con el encargo de Chandigarh (1951-55). Aunque ya había planos, decide, en medio de sus viajes, sustituir el inicial viario orgánico por otro de matriz reticular ordenado según un eje que se dirigía a las montañas y que, emulando su Ville Radieuse (1930), se remata con un área capitolina (fig. 1). En esta cabeza dirigente sitúa los edificios de los tres poderes (ejecutivo, legislativo y judicial) sobre una inmensa plaza: el capitolio se concibe como una gran explanada de "forma rectangular (...) compuesta de dos cuadrados iguales, cada uno dividido en cuatro sectores del mismo tamaño (...). Los cuadrados se encontraban cortados por (...) un canal de agua, un elemento simbólico de purificación”’3. Surge así el cuadrado en la base de los elementos clave en "un lugar que tiene una especie de magia en relación con las montañas y el cielo". Los croquis a color hechos en su primera visita así lo atestiguan.

Aunque los diseños preliminares sufren diversos cambios hasta la versión definitiva del capitolio, en todos ellos se mantiene la posición enfrentada entre las sedes parlamentaria y judicial bajo la mirada del ejecutivo (no construido), la disposición de las piezas sobre grandes superficies cuadradas, la presencia de un jardín de inspiración mogol (cuadrícula) en su linde superior y de un juego de relaciones geométricas entre los edificios que conjugan proporciones, formas, medidas y carga simbólica. Como señala Monteys: "En Chandigarh, la explanada, elemento clave de esta composición, se pone en valor a través de distintas operaciones, entre las que destacan las grandes superficies de agua reflejando en ocasiones las fachadas de los edificios" ${ }^{\prime 5}$. Veamos algunas de estas constantes que remiten al cuadrado como base de la composición, sea como vacío y plaza o como lleno y edificio.

Este gran foro se divide en dos cuadrados y, en el extremo norte del lado de unión entre ambos, se dispone la 'pirámide escalonada' del palacio del Gobernador (1951). El eje que une ambos cuadrados guía el conjunto: en el cuadrado este se dispone una plaza cuadrada — vacío - delante del palacio de Justicia (1952), mientras que, en respuesta especular, al oeste, este espacio está ocupado por la planta cuadrada del palacio de la Asamblea (1955) - lleno-; ambos edificios se multiplican con sus imágenes sobre el agua de los estanques cuadrados ${ }^{6}$ : láminas creadoras de un microclima que suaviza las temperaturas extremas. Un juego de alternancia de llenos y vacíos para los poderes legislativo y judicial mediante la simetría, y de jerarquía para el ejecutivo por su posición en cabeza.

El palacio de la Asamblea se emplaza en el centro del cuadrado de poniente y sus medidas (100x100m) reafirman su peso como centro de gravedad ${ }^{7}$. Este edificio se sirve de una retícula de pilares que, por adecuación al programa, presenta diversos módulos: el de la escala urbana (pórtico exterior), el de la escala doméstica (zona de oficinas) y el de la escala pública (el vacío interior que aglutina las dos cámaras: cuadrada y circular). Con este último módulo (de $8,15 \mathrm{~m}$ ) se despeja un espacio dentro del palacio legislativo donde se inscribe la sala circular de representantes, haciendo coincidir las diagonales de ambos cuadrados: del vacío interior y del lleno exterior (fig. 6).

Fuera de la plaza, el palacio del Gobernador también presenta planta cuadrada, el cual cabe con exactitud dentro del volumen casi cúbico que contiene la sala circular de diputados. Es más, no solo coinciden las medidas totales (41x41m), sino también las parciales del módulo único de la estructura $(8,15 \mathrm{~m})$, cuya cifra acusa la escala

\footnotetext{
${ }^{3}$ Casciato, M. [2013]. "Chandigarh: el paisaje de una nueva capital” en: AA.VV. Le Corbusier. An Atlas of Landscapes. Madrid: rev. Monografías, $N^{\circ} 176,2015$; pp: 26-33.

${ }^{4}$ Curtis, W.J.R. [1986]. Le Corbusier: ideas y formas. Madrid: Hermann Blume, 1987; p: 201.

${ }^{5}$ Monteys, X. [2005]. Le Corbusier. Obras y proyectos. Barcelona: Gustavo Gili, 2008; p: 162.

${ }^{6}$ Parra, J. "Imágenes y metáforas del agua en el pensamiento de LC". Valencia: ViA-arquitectura, No 10, 2001; pp: 8-15.

${ }^{7}$ Para las connotaciones simbólicas de la Asamblea véase: Curtis, W.J.R. [1986]. Ob. cit; pp: 188-201.
} 
pública de la 'casa' del Gobernador en lugar de referenciar una supuesta escala doméstica, vinculando más estrechamente ambos proyectos. Así pues, el palacio del Gobernador parece estar extraído del interior de la Asamblea (como si hubiese sido 'determinado' democráticamente desde dentro - alegoría-), constituido por un espacio modulado de $5 \times 5$ cuadrados. Superpuesto sobre este esquema compositivo emerge la estructura principal del palacio conformada por un cuadrado de dieciséis pilares que define una sala-tipo de nueve cuadrados (con múltiples posibilidades espaciales ${ }^{8}$ ) que hace coincidir 'topológicamente' la planta del palacio del Gobernador con la sala de lectura de la Biblioteca Nacional en París ${ }^{9}$, de Henri Labrouste, donde Le Corbusier se empapaba de textos e imágenes sobre arquitectura clásica y académica por recomendación de Auguste Perret ${ }^{10}$.

En esta continua alternancia de presencias y ausencias (donde el palacio del Gobernador se extrae del volumen de la cámara de representantes — cuadrado y círculo-, que se engloba en un cuadrado sobre la diagonal del palacio de la Asamblea, cuyo cuerpo se opone a la plaza y a los estanques del palacio de Justicia), la figura del cuadrado adquiere un protagonismo indiscutible (extendido a otros elementos del foro de los poderes, como la Mano Abierta y la Torre de las Sombras) en un juego compositivo que se desvanece, en parte, por la escala y por la inconclusión de las obras. Los cuadrados aquí son explanada y jardín, plazas y estanques abiertos —el vacíoy, también, son perímetro de planta y retícula de estructura, volúmenes y espacios cerrados —el lleno— con sus desplazamientos y compensaciones. El cuadrado marca y enmarca, cuadra y recuadra todos los elementos.

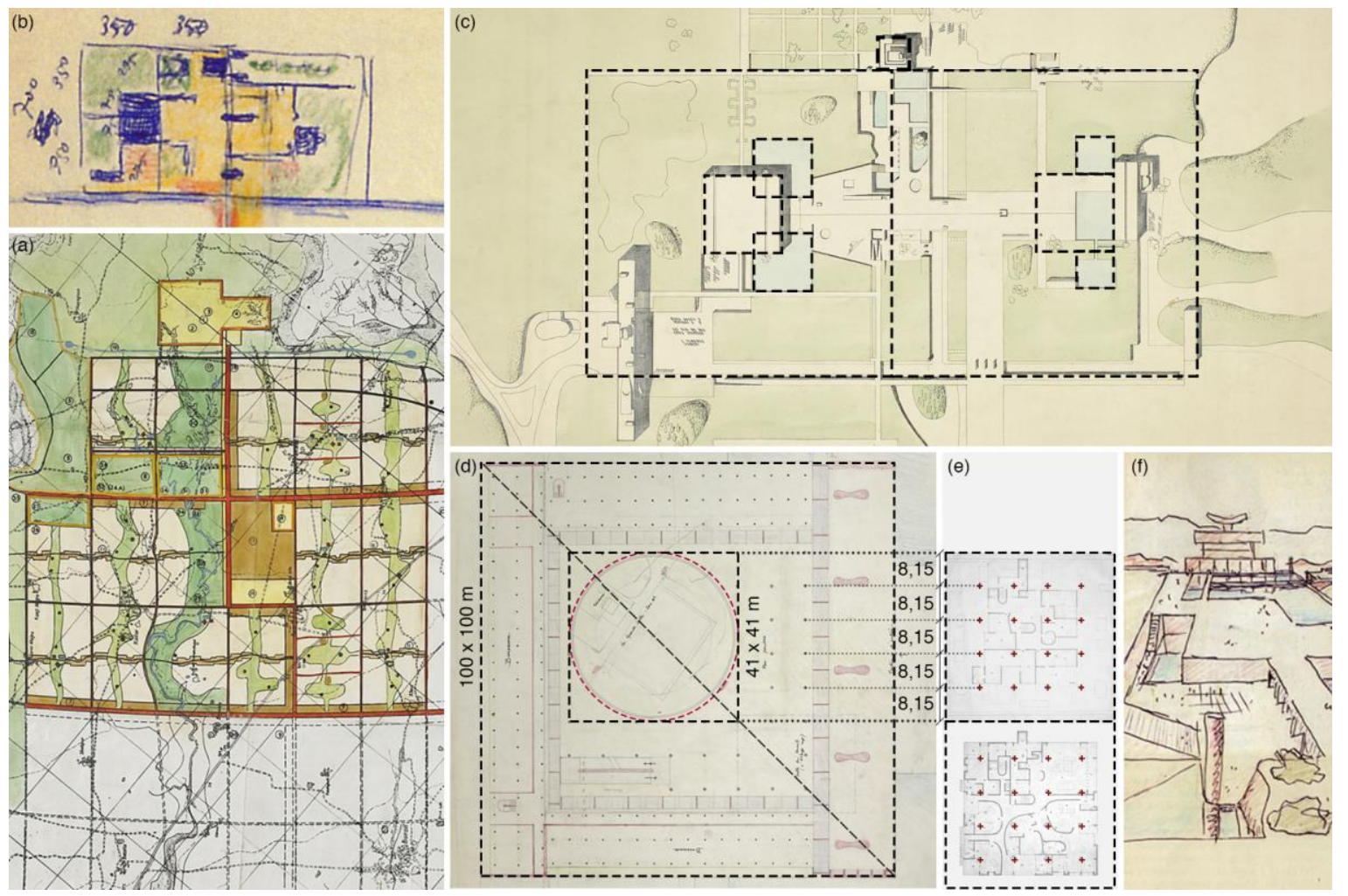

1. Capitolio de Chandigarh: (a) ordenación urbana (5.104@FLC-ADAGP); (b) boceto del capitolio (Casciato 2015); (c) planta de la explanada (5.151 FLC-ADAGP); (d) planta del palacio de la Asamblea (2.957@FLC-ADAGP); (e) plantas del palacio del Gobernador (3.792 y 3.794@FLC-ADAGP); (f) croquis palacio del Gobernador (Casciato 2015).

\footnotetext{
${ }^{8}$ Véase el palacio del Gobernador en: Monteys, X. La habitación. Más allá de la sala de estar. Barcelona: Gustavo Gili, 2014.

9 Este espacio presenta sus doce columnas del perímetro separadas del cerramiento de la sala de lectura iluminada cenitalmente con nueve lucernarios circulares; su concepción bien pudo influir en Le Corbusier. Puede consultarse: Frampton, K. Estudios sobre cultura tectónica. Barcelona: Akal, 1999; pp: 39-66.

${ }^{10}$ Cohen, J.L. [2013]. "Roma: una lección de paisaje urbano" en: AA.VV. Le Corbusier. An Atlas of Landscapes. Madrid: rev. Monografías, nº 176, 2015; pp: 26-33.
} 


\subsection{Museos de arte: boûte à miracles}

De todas las arquitecturas del capitolio punjabí impresiona el palacio de la Asamblea, tanto por su volumen exterior como por su esqueleto interior, todo uno. La rotunda planta del edificio no es un hito extraordinario en la trayectoria del maestro: la usa de modo insistente, una y otra vez, en los museos proyectados y construidos en su vida. Esta serie arquitectónica comenzaría en la trilogía del Mundaneum (1928) y los museos de arte contemporáneo y de crecimiento ilimitado (1931), se construiría en Ahmenabad (1951), Tokyo (1955), Cambridge-USA (1961) y Chandigarh (1964), y culminaría con el proyecto del centro internacional de arte de Erlenbach (1961); todos ellos albergaban colecciones de arte. Resulta casi inevitable relacionar estos museos con las mezquitas selyúcidas de Edirne y Bursa visitadas por Le Corbusier en 1911 que le causan una "Impresión inmensa y definitiva gracias al cuadrado perfecto" ${ }^{\text {"11 }}$ que las envuelve y contiene la cuadrícula isótropa de columnas (que eleva cúpulas idénticas).

Un análisis geométrico y métrico de los planos de seis de los museos citados revela proximidades entre ellos y una cierta evolución (fig. 2). Mientras el Mundaneum se concibe en volumen como un zigurat que se recorre por su interior, anunciando su reminiscencias sacras ${ }^{12}$, los demás museos comprimen este ascenso y lo sustituyen por un camino de suaves rampas que acompaña a las salas dispuestas en espiral respecto del centro (movimiento que se traslada hasta el exterior) configurando un cuerpo cúbico hermético, salvo en la planta a cota cero, que exige la iluminación cenital de las salas. Repetidamente, la solución de la estructura es una cuadrícula de columnas cuya distancia entre ejes deviene doméstica (rango 3,75-5,60m) y cuyas mallas de pórticos están seriadas $\left(\mathrm{n}^{\circ}\right.$ par de vanos); solo en dos casos estos espacios isótropos se vacían de columnas en el eje central para señalar el acceso, hecho que no deviene norma. Por último, mientras los museos no ejecutados presentan medidas diversas del recinto exterior (41x41-56x56m), los construidos acusan cifras cercanas (ca. 30m).

En síntesis, las características formales del tipo del museo serían: cuadrado exterior, cuadrícula de pilares interior, desarrollo de las salas de exposición en espiral desde el espacio central y volumen cúbico de hasta cuatro alturas: planta baja como "maraña de pilotes" (diáfana y abierta) y plantas superiores en desarrollo de las estancias (densas y cerradas). La luz llega al interior mediante claraboyas dispuestas en función de la propia orientación del edificio respecto de los cuatro puntos cardinales. Como señala J.L. Cohen "Le Corbusier ha reflexionado durante 30 años de manera incansable sobre el museo antes de darle una forma definitiva [...por lo que...] se puede ver en esta hipótesis, siempre mejorada, una especie de hipertrofia de Ville Savoye"13. Quizás esta idea se podría formular a la inversa y entender aquella villa como un museo — más que como una casadesde su origen, y todo museo es para recorrerlo y contemplar las obras expuestas, aunque en Poissy también se mire hacia afuera.

Estas arquitecturas encerradas entre los límites de una planta cuadrada con envoltura maciza no son objetos aislados: su programa se extiende más allá de la caja opaca en otros volúmenes menores (para teatros, salas de muestras, talleres, almacenes...) que se sitúan exentos respecto del perímetro cuadrado, salpicando las explanadas que rodean a los museos. Estas piezas, con sus posiciones desplazadas respecto de los planos de simetría del cuerpo cúbico, establecen una relación dinámica con los ejes de la retícula interior y del cuadrado marco exterior, adaptándose al movimiento de una espiral; ahora bien: las estructuras de estos volúmenes concuerdan con las de sus museos matrices, siendo parte de su expansión. Con esta visión, el museo puede interpretarse como una caja fuerte, blindada, que encierra tesoros artísticos, mientras que los elementos que

\footnotetext{
${ }^{11}$ Le Corbusier en: Daza, R. Tras el Viaje de Oriente. Charles-Édouard Jeanneret. Barcelona: Arquia, 2015; pp: 85 y 126.

${ }^{12}$ Eliade, M. [1956]. Lo sagrado y lo profano. Barcelona: Phaidós, 2015; p: 35, el ziggurat era "una montaña cósmica".

${ }^{13}$ Cohen, J.L. Le Corbusier, 1887-1965. El lirismo de la arquitectura en la era mecánica. Köln: Taschen, 2004; p: 97.
} 
aparentemente custodian su alrededor serían los contenedores que amplían el programa con otras actividades culturales y basculan en torno al museo; estos guardianes suelen ser de menor dimensión con el fin de no competir ante la supremacía del centro.

Con estos antecedentes se puede aventurar que, para Le Corbusier, el arte se integra en el territorio de lo sagrado: "Ver la Acrópolis es un sueño (...); y he aceptado desde hace mucho tiempo que aquí esté como el depósito del calibre sagrado, base de toda medida de arte" ${ }^{\prime 14}$. Museo de arte y templo sacro se aproximan en Le Corbusier ${ }^{15}$. Y para proteger lo sagrado, el hombre traza y construye un muro perimetral que precinta el lugar y lo aísla del exterior, salvo por una puerta, según Mircea Eliade: así han sido los espacios sacros de la mayoría de las diversas religiones a lo largo de la historia. También Ronchamp tiene ese muro casi ciego y protector. Ejemplos de arquitectura religiosa (de lo sagrado, lo inconmensurable o lo inexplicable) que abundan en esta dirección serían las iglesias de Le Tremblay (1929) y de Saint-Pierre en Firminy-Vert (1961), la capilla del hospital de Venecia (1965) o los túmulos funerarios de Delgado-Chalbaud ${ }^{16}$ (1951) y de su propia esposa (1959); todos estos casos -en proyecto u obra- quedan definidos por un perímetro cuadrado, como límite o frontera de separación entre dos mundos. Y todo elemento que defiende algo ha de ser fuerte y resistente, de aquí que estos ejemplos se levantasen o previesen en hormigón, ladrillo o mampostería. Para terminar, conviene recordar que "si toda obra de arte vuelve al origen de su género (...), toda obra de arte guarda un gesto de familiaridad con el origen" ${ }^{\prime 17} \mathrm{y}$, dado que los museos en Le Corbusier representan un lugar sagrado y sus recintos son cuadrados, quizás el cuadrado sea cofre de tesoros, centro de gravedad y boîte à miracles ${ }^{18}$; quizás esté en la génesis de toda su arquitectura.

\footnotetext{
${ }^{14}$ Jeanneret, Ch.E. [1911; 1965]. El viaje de Oriente. Valencia: COAATA y MOPU, 1984; p: 174.

15 Significativamente "Museos-Arquitectura sacra" es un capítulo en: Boesiger, W.; Girsberger, H. [1971]. Le Corbusier1910-1965. Barcelona: Gustavo Gili, 1987; pp: 233-285.

${ }^{16}$ Estas cuatro obras pueden verse en: Burriel, L.; Fernández-Cobián. Le Corbusier. Proyectos para la iglesia católica. Buenos Aires: Diseño Editorial, 2015.

${ }^{17}$ Quetglas, J. "Hacia Ronchamp” en: AA.VV. Le Corbusier, mensaje en una botella. Alicante: CTAA, 2011; pp: 147-157.

${ }^{18}$ Término usado por Le Corbusier para designar la Kaaba de La Meca y sus propios museos prototípicos; ver: Frampton, K. [1997]. Le Corbusier. Madrid: Akal, 2000; p: 139.
} 


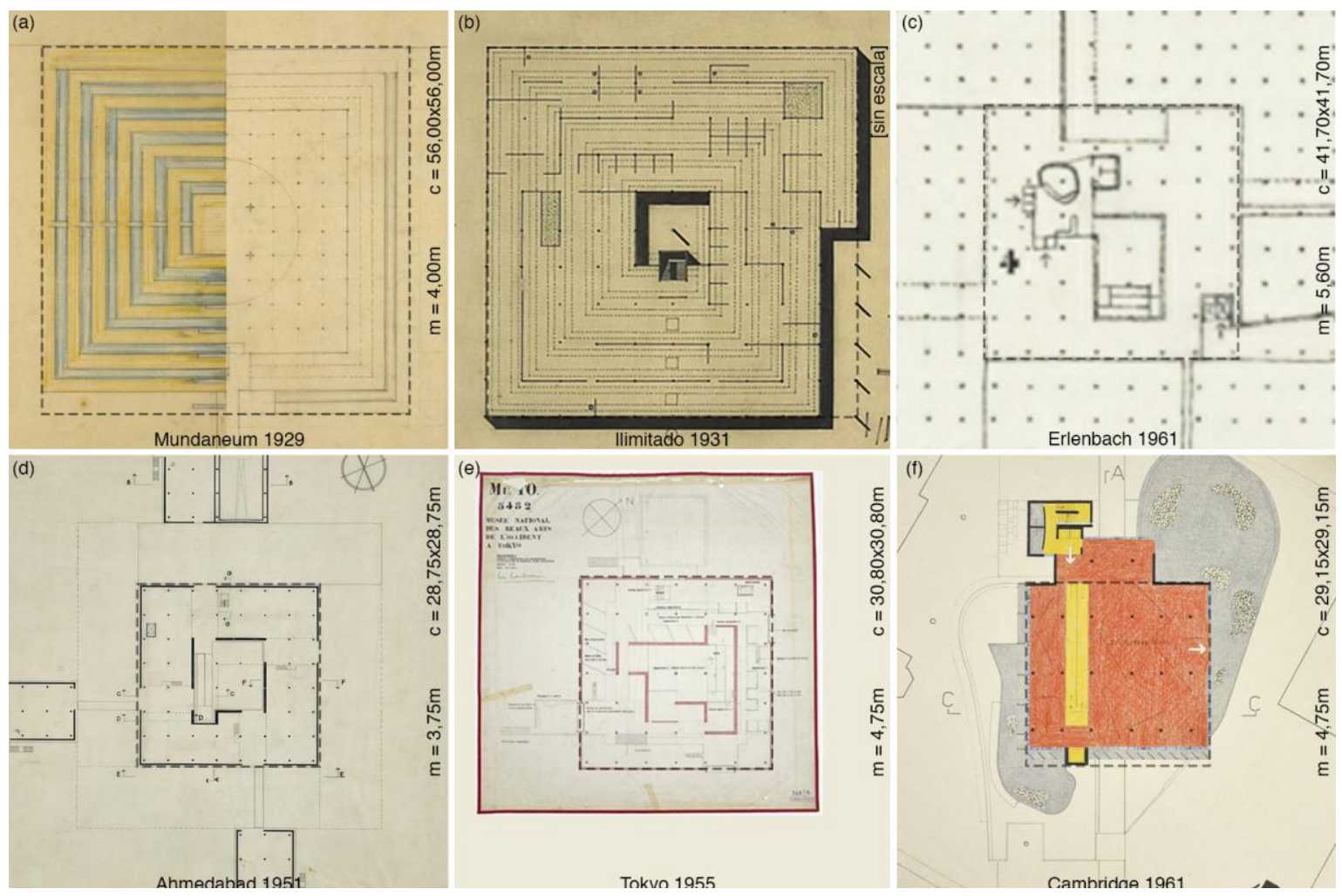

2. Museos: (a) Mundaneum 1928 (24.583@FLC-ADAGP); (b) Museo de Crecimiento Ilimitado 1931 (30.884@FLCADAGP); (c) Centro Internacional de Arte en Erlembah 1961 (23.421@FLC-ADAGP); (d) Museo en Ahmedabad 1951 (6.954 OFLC-ADAGP); (e) Museo en Tokyo 1955 (24.619@FLC-ADAGP); (f) Museo en Cambridge 1961 (31.268@FLCADAGP).

\subsection{Pabellones de exposición: cubos desmontables}

¿Y el origen de los templos que custodian lo sagrado? ¿Cuál sería según el maestro? En su libro Vers un Architecture (1923) propone como templo para las tribus nómadas "un lugar de espacio bien ordenado"19 que es una enorme choza. Este "templo primitivo" presenta una geometría regular, modulada y precisa, que adopta en planta la forma de dos cuadrados (10x20 módulos) en su recinto de verja exterior y de un rectángulo de casi dos cuadrados (4x9 módulos) en el perímetro de lona que encierra el propio templo. En el dibujo de la sección de esta tienda de campaña se regruesa el cuadrado inscrito en su espacio interior. Quizás sea casual la asociación de ideas, pero Le Corbusier, en casi todos los pabellones para exposiciones eventuales que diseña, dado su carácter de evento transitorio y efímero, adopta el tipo de 'cabaña desmontable' y, en lógica consecuencia, los materiales son más ligeros: perfiles, chapas y cables metálicos, superficies y cuerdas textiles. La mayoría de estos pabellones feriales acogía en su interior muestras impactantes en lo visual (imágenes, luces, sonidos) y novedosas en lo artístico (dioramas, urbanismo, fotografía, cine). Contenido (arte de vanguardia) y contenedor (pabellón temporal) entran en resonancia y su geometría, como en los museos, comienza en el cuadrado. Y como corresponde a todo museo, se requiere de un recorrido para observar las piezas o los objetos allí depositados, de aquí que la geometría esvástica sea la base de muchas de sus distribuciones. La serie de estos pabellones incluiría, al menos, seis obras (fig. 3): Les Temps Nouveaux (1937, París), los pabellones de Francia (1937 Lieja y 1939 París), el proyecto para la Exposition Synthèse des Arts Majeurs (1949, Porte Maillot, París), el 'palacio' de exposiciones Ahrenberg (1962, Estocolmo) y la Casa del Hombre (1961-67, Zurich). En esta lista se

\footnotetext{
${ }^{19}$ Le Corbusier [1923]. Hacia una arquitectura. (1 ${ }^{\text {a }}$ reimp). Barcelona: Apóstrofe, 1998; p: 53.
} 
establecen dos grupos: con la planta distribuida sobre un cuadrado (pabellones anteriores a la IIGM) y con la planta organizada a partir de dos cuadrados adosados por un lado (posteriores a la IIGM). Todos se erigen con estructuras de acero: pueden ser trasladables.

En el primer grupo, las cubiertas de los pabellones evolucionan desde un andamiaje de tensores que fijan los puntales de sostén atirantados a tierra (y que evocan la imagen del templo primitivo) hasta una estructura de pilares y celosías curvas en vuelo. A su vez, la planta del cuadrado se multiplica hasta los dos o los cuatro cuadrados y la cuadrícula inicial de cables a tracción se sustituye por pilares en los puntos medios de los cuadrados (sean uno o cuatro). El interior de estos espacios expositivos cúbicos se secuencia mediante una promenade que transcurre sobre un juego de rampas en espiral: rampas que en Les Temps Nouveaux se adosan al perímetro vaciando el centro y que en los otros dos pabellones generan una plataforma central elevada desde donde contemplar la muestra. En el segundo grupo, la planta tipo presenta un perímetro exacto de dos cuadrados, con seis pilares situados en sus puntos medios exteriores y con una cubierta unitaria en "forma de caparazón con apoyo a medio vuelo y esquinas en voladizo" ${ }^{20}$. Muchos de estos pabellones fueron resueltos por Le Corbusier como si de un tipo genérico de validez universal se tratara: sistematizado para construirse en cualquier parte y acoger cualesquiera objetos. Sin embargo, en estos pabellones, las rampas establecen recorridos que entran y salen del cuerpo de la cubierta conduciendo a los visitantes a través de los dos niveles, y describen un travelling al exterior que recuerda el del interior en sus primeras casas y villas en las que basó los cinco puntos de la "Nueva Arquitectura"; no en vano, el pabellón de Zurich, que estaba pensado como un prototipo de espacio para exposiciones $^{21}$, desarrollaba un programa de vivienda en dúplex. Llama la atención esta doble conexión de los pabellones: con los museos, como contenedor y antecedente, y con el hábitat humano, como contenido y destino en este último caso.

Es interesante este circuito que se retroalimenta: templos primigenios que son tiendas de campaña; tiendas que inspiran pabellones y se adecúan como casas que, en su origen, lo eran a imagen y semejanza de las moradas de los dioses, por lo que lo sagrado vuelve a estar omnipresente, y la Casa del Hombre es un museo de arte que se vuelve cabaña desmontable ${ }^{22}$. Templo, tienda, pabellón, cabaña, templo: todo va y vuelve — ¿lo pensaría así Le Corbusier?) - . De hecho, el pabellón de Zurich se compone de dos cubos dentro del volumen generado por la cubierta sobre la planta de dos cuadrados adosados; estos hexaedros están separados por la rampa y se dimensionan ya con el modulor (module+section d'or), en cuya sistematización de medidas a escala humana había trabajado el maestro en plena IIGM y que dio a conocer en los libros El Modulor (1948) y El Modulor II (1953); libros de formato cuadrado. A lo largo de sus páginas se explica cómo a partir de un cuadrado inicial se genera su sección áurea y su diagonal abatida dando lugar a la figura de un doble cuadrado $(2 \times 1,13=2,26 \mathrm{~m}$ donde se inserta un hombre con la mano alzada) y cuyo desarrollo geométrico se relaciona con la razón de la serie de Fibonacci ${ }^{23}$, proporcionando las medidas humanas para la arquitectura.

Sin embargo, el pabellón por excelencia sería el refugio para las vacaciones que Le Corbusier se construye para sí mismo en Cap Martin (1951): Le Cabanon, una de las primeras obras donde puso en práctica el modulor. El diminuto volumen, casi cúbico y con pendiente a una sola agua, cuenta con dos pequeñas ventanas cuadradas y, en su austeridad, recuerda a una celda monacal donde se concentra un programa de existenzminimum individual distribuido en espiral. Está ejecutado en su totalidad en madera que, en las fachadas, muestra la corteza de sus troncos primigenios. Salvo por la cubierta de fibrocemento, esta arquitectura seca (sin agua, sin cemento) y

\footnotetext{
${ }^{20}$ Frampton, K. [1997]. Ob. cit.; p: 133.

${ }^{21}$ Dumont, C.; Benton, T. Le Pavillon de Le Corbusier pour Zurich.... Zurich: Lars Müller Publishers, 2013.

${ }^{22}$ Frampton, 2000, ob. cit.; pp: 131-146. Sitúa el pabellón Philips (1958) como "cima y punto final” del "Arte Sacro" de LC.

${ }^{23}$ Le Corbusier [1948 y 1953]. El Modulor y Modulor 2. (3ª ed.). Barcelona: Poseidón, 1980; pp: 31-64.
} 
desmontable, bien podría ser una 'cabaña para el hombre' en medio del bosque, de no ser porque esta construcción se adosa a la civilización en el testero sudeste del restaurante L'Etoile de Mer, sobre el acantilado y frente al mar. Este cuarto para el retiro del maestro (cuyas experiencias de soledad y silencio Le Corbusier repite a lo largo de su existencia) puede entenderse como un ejercicio de síntesis por el que el frío pabellón se transmuta en una cálida cabaña como hogar del artista - la casa -, y toda ella condensada en un solo cuadrado (de $3,66 \times 3,66 \mathrm{~m})$.

(a)
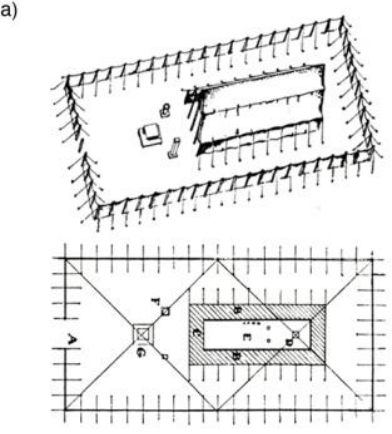

Templo primitivo (1923)

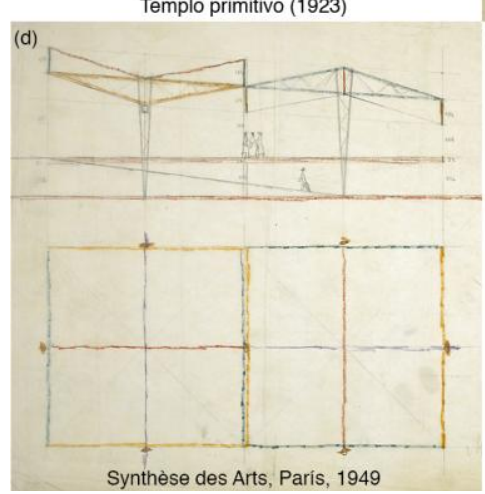

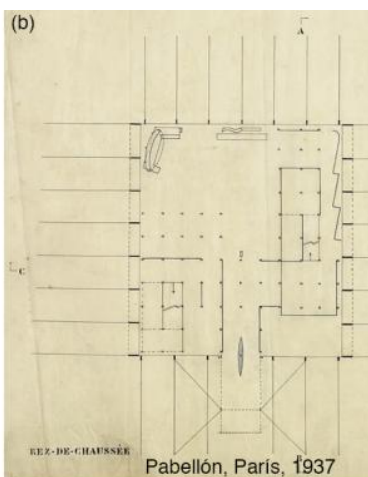

(e)

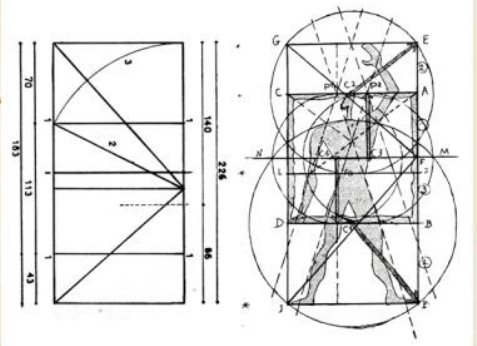

El Modulor, 1942-46

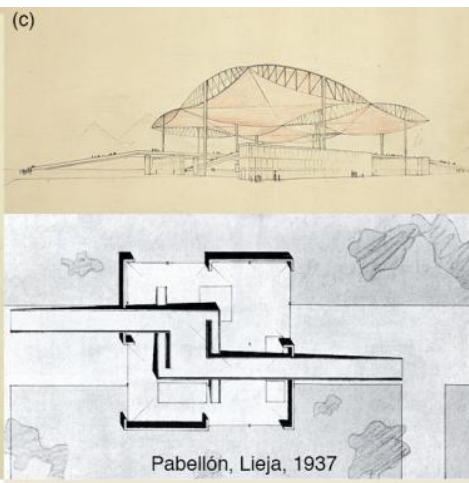

(f)

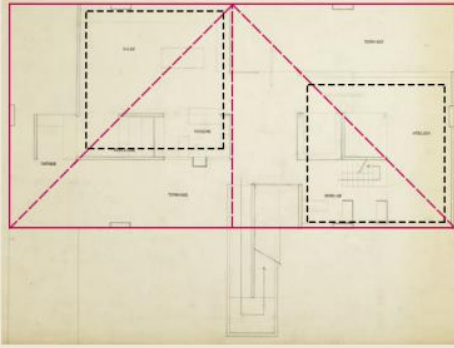

Pabellón, Zúrich, 1961

3. Pabellones: (a) templo primitivo según LC en 1923 (LC 1998); (b) pabellón Les Temps Nouveaux 1937 (783 OFLCADAGP, Monteys 2005); (c) pabellón del Agua Lieja 1939 (24.290@FLC-ADAGP); (d) pabellón Synthèse des Arts 1949 (18.185@FLC-ADAGP); (e) el Modulor 1942-46 (LC 1980); (e) pabellón Casa del Hombre 1961 (21.078@FLC-ADAGP).

\subsection{Casas cuadradas, cajas cúbicas}

Si hay alguna 'casa' en la que se resuma la trayectoria de Le Corbusier, esta es la villa Savoye (1928-29), cuyas cualidades visuales platónicas ${ }^{24}$ la han convertido en un icono de la modernidad. Se trata de una 'casa' concebida como un pallazo exento (con habitación para el servicio doméstico): en los bajos están los útiles (máquinas), en el piano nobile la residencia (familiar) alrededor del cortile, y en la planta alta el belvedere lúdico (terraza-jardín con vistas). Además, esta villa de reminiscencias clasicistas anticipa recursos formales y distributivos propios de sus museos: en ella "Le Corbusier reafirma, con la imposición del cuadrado, las cualidades espirales de la asimetría, la rotación y la dispersión periférica" ${ }^{25}$. Aunque su perímetro no es un cuadrado exacto, su retícula base (20x20m) definida por los pilares exentos (5m) sí lo es, como también lo es el patio tangente a su fachada oeste (10x10m). Quizás se pueda afirmar que tanto Le Cabanon como la villa Savoye son casas cuadradas con vocación cúbica.

\footnotetext{
${ }^{24}$ Rowe, C. [1947]. Manierismo y arquitectura moderna y otros ensayos. Barcelona: Gustavo Gili, 1980.

${ }^{25}$ Frampton, K. [1980]. Historia crítica de la arquitectura moderna (9a ed.). Barcelona: Gustavo Gili, 1998; p: 159.
} 
El antecedente de la villa Savoye es la casa Meyer (1925), donde comienza la promenade architectural en el ámbito humano. El programa definitivo se despliega en cuatro plantas con la rampa pegada al linde; el contorno de todas ellas es un cuadrado que se vacía en una esquina por un espacio cuadrado, con la diagonal de ambos coincidiendo (como después en Chandigarh o Zurich). La distancia a la que se sitúa la fachada posterior dentro de la parcela ha sido elegida por Le Corbusier para hacer de la planta un cuadrado. Esta preferencia del maestro por la más elemental de las figuras planas es una práctica que le sirve para encuadrar muchas de sus residencias, sean casas (entre medieras o en fila) o villas (pareadas o aisladas). De la primera tipología sería representativa la casa Cook (1925) en la que el cuadrado se inserta entre la fachada posterior y el pilar exento de la parte delantera, usando el soporte central para dividir la superficie en cuatro cuadrantes. Y de la segunda tipología sería ilustrativo el conjunto de pareadas Loucher (1929), donde los programas mínimo y máximo se resuelven en uno o dos niveles y, recípocamente, las distribuciones se inscriben dentro de uno o de dos cuadrados (resultado este último de adosarse dos por uno de sus lados convertido en un grueso muro intermedio); en estas viviendas destaca que algunos aseos presenten su perímetro cuadrado exento (de esquinas curvas), acusando dentro la forma de fuera.

La larga lista de ejemplos de casas y villas resueltas a partir del cuadrado (como contorno o como geometría de la malla de estructura) expresa bien el calificativo de 'sintético' otorgado al maestro por su proceso de proyecto, ya que el programa se 'cuadra' en formas previas elegidas por él (fig. 4). Evidencia de esta práctica es la solución dada a la casa Curutchet (1949) que se resuelve, desde los primeros bocetos, en un cuadrado encajado al fondo del solar; planteamiento que se mantiene hasta el proyecto definitivo (reforzado por la cuadrícula de pilares), solo que, para entonces, de la residencia privada se ha desgajado la consulta médica volcada sobre una calle de La Plata. Sugerente resulta la sección de esta casa que, en la parte de la vivienda, se inscribe en un cuadrado y define una caja cúbica; este cubo, que se intuye, queda visto en las villas que construye en Ahmedabad en la década siguiente.

Para alcanzar el volumen compacto del hexaedro se requieren plantas, fachadas y secciones también cuadradas, no necesariamente como límites o marcos, basta con que esta forma regular se perciba visual o espacialmente. En este sentido conviene comprobar cómo la sección por la diagonal de la planta de las casas en serie para Artesanos (1925), que parte de una planta cuadrada (7x7m), acusa un perfil de dos cuadrados. Cómo las fachadas de los bloques de viviendas del barrio de Pessac constituyen una composición en damero (de 5x5m). O cómo el alzado y la sección de la villa Baizeau (1928) acusan su perímetro cuadrado. Si se analiza con detenimiento los planos de esta villa —alzado y sección, que responden a la misma proyección ortogonal—, se comprueba que el borde exterior que rodea los forjados está conformado por la sucesión de cuatro cuadrados que deslizan unos junto a otros sobre un eje vertical situado en la mitad de ambas superficies. En este caso, además, se materializa una novedad espacial: si las retículas neutras de pilares exentos revelan la fluidez horizontal del espacio de la planta libre, esta sección sugiere la expansión de esta cualidad también en sentido vertical.

Demostrada la persistencia del cuadrado, tanto como generador de plantas, alzados y secciones como del espacio cúbico, surge otro aspecto que abordar relativo a la presencia del cuadrado como origen de las distribuciones y de las tramas reticulares de pilares de la estructura, el cual revela la serie de relaciones básicas proporcionales en planta en la que basa Le Corbusier sus diseños. Veamos estos mecanismos en las dos viviendas para el barrio experimental de la Weissenhofsiedlung de Stuttgart (1927): las variantes 'Citrohan' y 'Dom-Ino'. En la casa Citrohan (casa, porque estaba pensada para adosarse), las cuatro plantas de la misma quedan definidas por una estructura de 4 pórticos paralelos (entre ejes $=5 \mathrm{~m}$ ) que definen dos cuadrados adosados, siendo las proporciones que vinculan la geometría de la estructura y la de la planta la serie 1:1 y 1:2, la cual se completa con 1:4 al sumar la escalera. En la casa Dom-Ino (casa porque, a pesar de las ventanas de los testeros, son dos las viviendas 
construidas con intención de crear una fila) se emplea un pórtico similar (girado $90^{\circ}$ respecto de fachada), pero, para completar la figura ordenadora del cuadrado, se recurre al cerramiento de fachada de manera que el perímetro de cada vivienda queda definido por 2 y 2,5 cuadrados, repitiéndose modulaciones y proporciones. $\mathrm{Al}$ margen de los múltiples ejemplos que ilustran estos engranajes que vinculan la estructura con los perímetros de los cerramientos a través del cuadrado (y con ellos la definición de volúmenes cúbicos), interesa destacar cómo el sistema de proporciones que maneja Le Corbusier es de raíz clásica y se anticipa en las propias viviendas al empleo de los trazados reguladores que, a veces, se aplican al exterior. Y, también, cómo este sistema de razones simples $(1: 1,1: 2,1: 4)$ ha estado presente siempre como instrumento de composición en los diversos temas abordados (incluso en urbanismo), tanto en las cuadrículas base como en los nuevos tipos arquitectónicos generados.

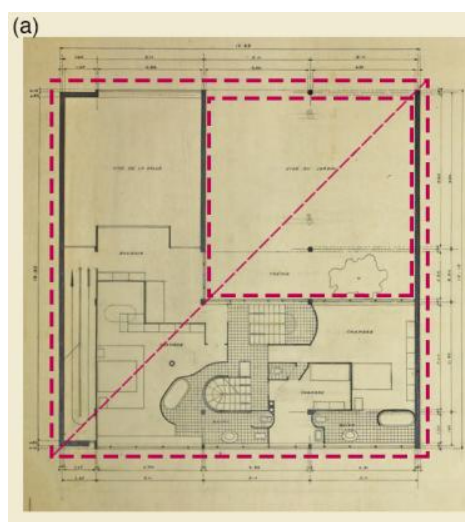

(e)

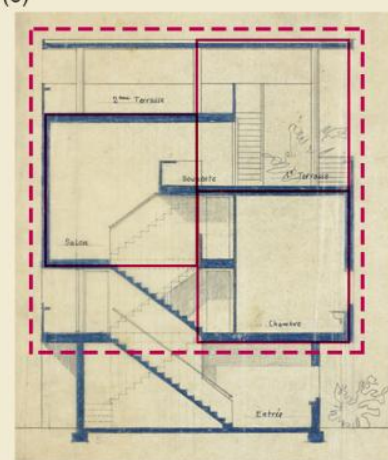

(b)

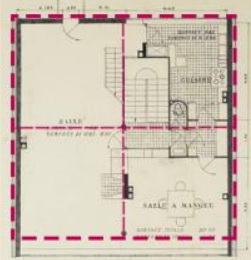

Casa Cook, 1925

Casa Meyer, 1925

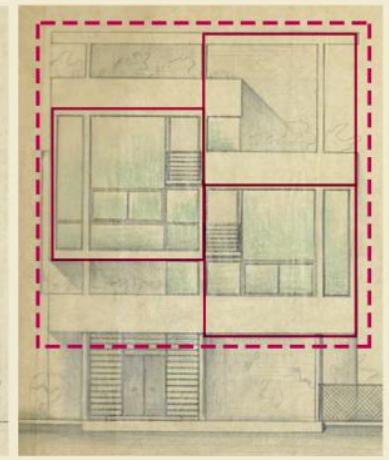

Villa Baizeau, 1928 (c)

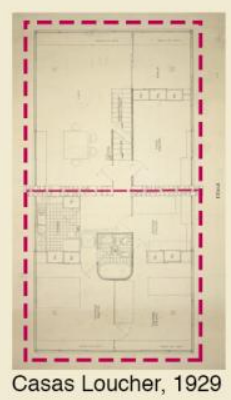

Villa Savoye, 1928

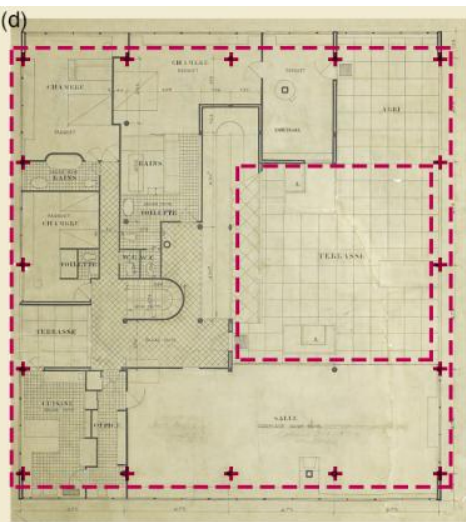

(f)

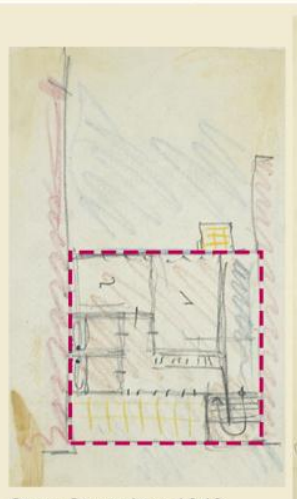

Casa Curutchet, 1949

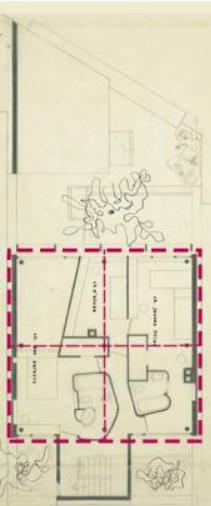

3. Casas y villas: (a) Casa Meyer 1925 (10.370@FLC-ADAGP); (b) Casa Cook 1925 (8.294@FLC-ADAGP); (c) Casas Loucher 1925: vivienda en dos plantas (18.236@FLC-ADAGP); (d) Villa Savoye 1928 (19.440@FLC-ADAGP); (e) Villa Baizeau: sección y alzado 1928 (8.511 y 8.475@FLC-ADAGP); (f) Casa Curutchet: boceto y planta del segundo nivel 1949 (30.542 y 12.101 OFLC-ADAGP).

\section{De regreso al origen (conclusiones)}

Alcanzado este punto procede volver sobre nuestros cuatro temas: capitolios, museos, pabellones y casas, algo que Le Corbusier hacía a menudo. En relación al capitolio de Chandigarh, el recurso al cuadrado (doble) sirve tanto para definir la plaza pública como para subrayar la misma mediante la adopción de esta forma para sus edificios representativos: los palacios de la Asamblea y del Gobernador; muy singular resulta la igualdad de medidas del módulo de la estructura y la coincidencia de ciertos perímetros entre ambos, constatando que el volumen de la residencia del ejecutivo se ha extraído del interior de la cámara de representantes en un juego de llenos y vacíos complementarios. En cuanto a los museos, se ha evidenciado la persistencia de la forma 
cuadrada, ahora como generadora de un volumen estanco y hermético, demostrando la afinidad que para el maestro se establece entre los territorios del arte y de lo sagrado, trazando un muro ciego a su alrededor; estas cajas de seguridad se sostienen gracias a una cuadrícula neutra de soportes. Bastante diferente de cuanto sucede en sus pabellones para exposiciones temporales, donde la estructura es la protagonista al dejar las trazas vistas del cuadrado definiendo el volumen exterior y el espacio interior. Pabellones-cubo que rememoran el arquetipo de arquitectura desmontable y transportable: tienda y cabaña, templo y casa de los pueblos nómadas. Este periplo concluye (o se inicia) en el interior del hábitat humano, en sus residencias, sean casas o villas (todas 'palacios'), donde el cuadrado se presenta tanto en planta, alzado y sección, como en sus retículas base de estructura definiendo estancias, contornos, espacios y volúmenes. Este análisis puede calificarse de 'Elogio del Cuadrado' por la permanencia del mismo a lo largo del tiempo, cuya poética (en sus mecanismos de composición, que anteceden a los trazados reguladores y al propio modulor) ya estaba avanzada en los años 20 , incluso antes (fig. 5).

Le Corbusier, que siempre quiso ser pintor, que siempre viajaba con cuadernos y que siempre dibujaba, pintó en 1918 en París, con 31 años, un óleo sobre lienzo (de 0,70x0,68m) titulado La Cheminée (“La Chimenea”), en cuyo reverso se puede leer "Ceci est mon premier tableau" ("Esta es mi primera tabla", de madera); está firmado por 'Jeanneret' que, por entonces, aún no había adoptado el nombre de Le Corbusier. El cuadro recrea un cubo blanco que queda mucho más cerca del Cubismo que de su expresión ante la Acrópolis de Atenas: "El Partenón, (...) entroniza su cubo, frente al mar" ${ }^{\prime 2}$. En ambos casos confiesa su seducción por la geometría elemental que contienen estos hexaedros brillantes. Un par de años antes, en 1916, había proyectado la villa Schowb en su Chaux-de-Fonds natal. Esta villa, de planta cuadrada en su perímetro principal, define un volumen cúbico al exterior que configura su estructura con una cuadrícula de pilares (3x3 módulos, 16 soportes) que parte de un cuadrado central (con luz coincidente con la villa Savoye) ${ }^{27}$, cuya concatenación de espacios acusa influencias desde los croquis reflejados en sus cuadernos del viaje a Oriente ${ }^{28}$.

Quizás sea más significativo que un par de años antes, en 1914, proyectase la célula del sistema Dom-Ino ('Casa e Innovación'), como un juego de piezas combinables, definiendo con precisión las plantas tipo de las viviendas dúplex y la estructura de sostén. Cada pieza de este 'juego' era una casa (de sección cuadrada y que se podía adosar por sus testeros) cuyo armazón de hormigón armado estaba conformado por una retícula de 8 pilares dispuestos según 2,5 cuadrados: la relación 1:1 era para las estancias mientras que la de 1:2 albergaba la escalera interior; remataba este manifiesto de independencia de la piel envolvente respecto del esqueleto sustentante la separación de los dos planos de las fachadas a una distancia de 1:4 del módulo. Aquí quedaba ya fijada esa serie de relaciones simples y clásicas de 1:1, 1:2 y 1:4. Por otro lado, en la esquina derecha del plano de la cónica donde se recrea una agrupación de casas Dom-Ino, puede distinguirse que el espacio público alrededor del cual se reúnen, sea una plaza o un jardín en lo alto de una loma, tiene planta de cuadrado doble. Este pintoresquista dibujo sería retocado por Le Corbusier para la publicación de este sistema y de sus revolucionarias ideas: se suprimieron los arcos y los típicos cipreses que evocaban su fuente directa, la cartuja de Ema, en Florencia, encaramada en una colina. Allí había permanecido por un mes en 1907, cuando tenía 20 años, para ejercitar la

\footnotetext{
${ }^{26}$ Jeanneret, Ch.-E. [1911; 1965]. Ob. cit.; p: 170.

${ }^{27}$ En la villa Schowb (como en la casa Citrohan), la distancia de $5 \mathrm{~m}$ lo es entre las caras de los pilares, mientras que, en la villa Savoye, la distancia de $5 \mathrm{~m}$ lo es entre ejes (ee) en una versión intermedia y de 4,75m en la versión final. A lo largo del presente artículo, cuando hablamos de módulo o intereje (ee) referimos, en general, la distancia entre ejes de pilares.

${ }^{28}$ Jeanneret, Ch.-E. [1911]. Voyage d'Orient. Carnets. Milano: Mondadori, 2002 (1987). Este es un camino interesante: los aprendizajes que subyacen en Le Corbusier procedentes de las iglesias ortodoxas y de mezquitas 'turcas'; estas últimas se sintetizan en dos tipos: reticulares (cuadrícula de pilares y cúpulas circulares) y de espacio central (de influencias bizantinas).
} 
vida en soledad ${ }^{29}$ y de allí surgirían muchas ideas arquitectónicas porque los monjes no vivían en celdas, sino en casas individuales (básicamente cuadradas en planta y cúbicas en el volumen) dispuestas junto al corredor del claustro y cada una con su jardín privado e independiente; las lecciones de este lugar serían otro capítulo ${ }^{30}$.
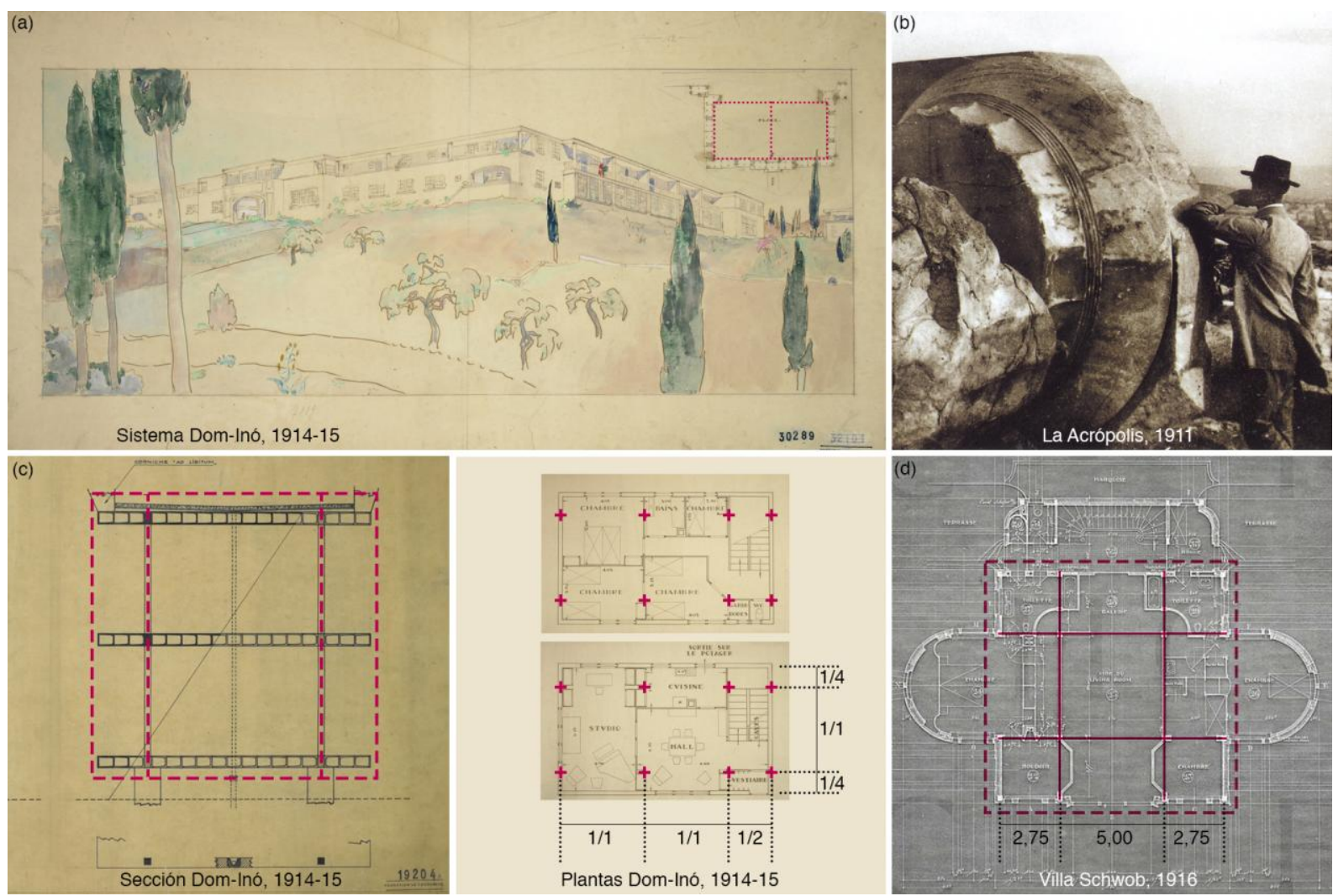

5. Orígenes: (a) perspectiva conjunto de viviendas Dom-Inó 1914-15 (30.289@FlC-ADAGP), (b) Le Corbusier en la Acrópolis de Atenas 1911 (Cohen, 2015), (c) sección cédula Dom-Inó (19.201@FLC-ADAGP), (d) plantas célula-vivienda Dom-Inó (19.172 y 19.211@FLC-ADAGP), (e) planta segundo nivel de la villa Schowb 1916 (33.172@FLC-ADAGP).

La fascinación de Le Corbusier por las construcciones coronando la cima de montañas - acrópolis- queda patente en sus cuadernos de viajes, muy especialmente en los Carnets de su Viaje a Oriente en 1911 que le llevaría por Turquía, Grecia e Italia, el cual, además de ser su primer gran viaje de estudios (y diversión), con 23 años, se revelaría iniciático, ya que el propio Le Corbusier revisita sus blocs el mismo año de su muerte y los prepara para su publicación (1966). De entre todas las ciudades y arquitecturas que le esperaban en el trayecto, son Atenas y el Partenón las que más expectación levantan en su ánimo: “PPero por qué (...) debo designarlo como el Maestro incontestable el Partenón (...)?”31. La geometría, la técnica y la perfección modular y de proporciones le sobrecogen: "A la izquierda del Partenón columnas enteras están caídas, echadas abajo (...). Su diámetro sobrepasa la altura de un hombre....”2 ; impresión que recoge en una fotografía en la que él mismo, de cuerpo entero, está apoyado sobre un capitel, oponiendo su silueta humana al círculo del equino que atraca contra el ábaco cuadrado: imagen que anticipa en tres décadas su modulor. Parte del secreto de las piedras del

\footnotetext{
${ }^{29}$ Gargiani, R. [1987]. "Vita di Charles-Édouard Jeaneret-Gris, Le Corbusier” en Brooks, A.H. (ed). Le Corbusier. (5ª ed.). Milano: Electa, 2001; pp: 292-325.

${ }^{30}$ Benton, T.; Cohen, J.L. (eds.). [2008]. Le Corbusier Le Grand. London: Phaidon Press Limited, 2014; pp: 19-84.

${ }^{31}$ Jeanneret, Ch.-E. [1911; 1965]. Ob. cit.; p: 175.

${ }^{32}$ Ibídem; p: 181. Estas expresiones y la foto de LC apoyado sobre el capitel dórico pueden evocar la planta de la Asamblea de Chandigarh: el cuadrado que contiene la sala circular presenta 20 columnas, número igual a las estrías del dórico del Partenón.
} 
Partenón es posible intuirlo si se visita y se mide su recinto interior, sagrado. Cuando uno se asoma al borde del estilóbato de un templo griego descubre que modulación y construcción son una misma cosa, y lo que se extiende ante la mirada es la cuadrícula de las losas cuadradas de las bases de los pilares circulares exentos situados en su perímetro, con su volumen, su materia y su pulcra ejecución. Le Corbusier entró al Partenón por en medio del cuarto y el quinto fuste, justo a eje del templo. Años después, en 1923, escribiría: "Porque los ejes, los círculos, los ángulos rectos, son las verdades de la geometría, son los efectos que nuestros ojos miden y reconocen" 33 .

Si tomamos como cierta la metáfora que sobre la vida traza F. Scott Fitzgerald en un breve relato que publica 1921, donde describe la historia vital del protagonista al revés del ciclo natural, se podría considerar que la vida resulta casi simétrica respecto del eje que pasa por el punto en que se alcanza la mitad de la edad que se vive. Bajo esta perspectiva, la anterior afirmación del maestro la realiza cuando tiene 36 años, en el ecuador de su existencia, en plena madurez, por lo que va a gobernar su amplia producción a partir de entonces: un sustrato compositivo académico que verifica en la historia y en diversas culturas. Charles-Édouard Jeanneret se está convirtiendo en Le Corbusier — arquitecto y pintor-, en quien se funden conocimientos de viajes, influencias clasicistas y experiencias cubistas. Aunque muchas claves de su arquitectura, según él mismo, residen en su pintura, el léxico básico al que recurre remite a la geometría del cuadrado de principio a fin, de la villa Fallet a la Casa del Hombre. La persistencia del cuadrado como tema de composición a lo largo de su trayectoria no supone un fin, sino que el cuadrado — en tanto que módulo ordenador, marco límite o cuadrícula base- se configura como el medio en sus procesos de diseño, porque le ofrece la seguridad de controlar las formas (derivadas mediante proporciones de ascendencia clásica) combinadas con los principios de libertad explorados por las vanguardias artísticas. El propio cuadrado acusa simbolismos arcaicos en una síntesis evolutiva entre arquitectura y arte en la que trabajaría el resto de su vida ${ }^{34}$ tejiendo un inmenso tapiz de fils du Temps.

\section{Bibliografía}

AA.VV. Le Corbusier. An Atlas of Landscapes. Madrid: rev. Monografías, № 176, 2015.

Benton, T.; Cohen, J.L. (eds.). Le Corbusier Le Grand. London: Phaidon Press Limited, 2014.

Boesiger, W.; Girsberger, H. Le Corbusier1910-1965. Barcelona: Gustavo Gili, 1987.

Brooks, A.H. (ed.). Le Corbusier. (5 ${ }^{\text {a }}$ ed.). Milano: Electa, 2001.

Burriel, L.; Fernández-Cobián. Le Corbusier. Proyectos para la iglesia católica. Buenos Aires: Diseño Editorial, 2015.

Calatrava, J. (ed.). Doblando el Ángulo Recto: 7 ensayos en torno a Le Corbusier. Madrid: Círculo Bellas Artes, 2009.

Calatrava, J. "Una visión del mundo. Le Corbusier: The Art of Postcards". Madrid: Arquitectura Viva, №170, 2015.

Cohen, J.L. Le Corbusier, 1887-1965. El lirismo de la arquitectura en la era mecánica. Köln: Taschen, 2004.

Curtis, W.J.R. Le Corbusier: ideas y formas. Madrid: Hermann Blume, 1987.

Daza, R. Tras el Viaje de Oriente. Charles-Édouard Jeanneret-Le Corbusier. Barcelona: Fundación Arquia, 2015.

\footnotetext{
${ }^{33}$ Le Corbusier [1923]. Ob. cit.; p: 54.

${ }^{34}$ Calatrava, J. "Le Corbusier, 1955: en los alrededores de El poema del Ángulo Recto" en: Calatrava, J. (ed.). Doblando el Ángulo Recto: 7 ensayos en torno a Le Corbusier. Madrid: Círculo Bellas Artes, 2009; pp: 9-39.
} 
Dumont, C.; Benton, T. Le Pavillon de Le Corbusier pour Zurich. Modèle et prototype d'un espace d'exposition idéal. Zurich: Lars Müller Publishers, 2013.

Eliade, M. Lo sagrado y lo profano. Barcelona: Phaidós, 2015 (trad. L. Gil Fernández y R.A. Díez Aragón).

Fondation Le Corbusier. Le Corbusier Plans, 1905-1965. (16 vols.). Paris: Echelle-1, 2005.

Frampton, K. Historia crítica de la arquitectura moderna (9ª ed.). Barcelona: Gustavo Gili, 1998.

Frampton, K. Le Corbusier. Madrid: Akal, 2000 (trad. J. Calatrava).

Frampton, K. Estudios sobre cultura tectónica. Barcelona: Akal, 1999 (trad. A. Bozal)

Jeanneret, Ch.E. El viaje de Oriente. Valencia: COAATA y MOPU, 1984.

Jeanneret, Ch.-E. Voyage d'Orient. Carnets. Milano: Mondadori, 2002.

Le Corbusier. Hacia una arquitectura. (1 $1^{\text {a }}$ reimp). Barcelona: Apóstrofe, 1998.

Le Corbusier. El Modulor y Modulor 2. ( $3^{\mathrm{a}}$ ed.). Barcelona: Poseidón, 1980.

Monteys, X. Le Corbusier. Obras y proyectos. Barcelona: Gustavo Gili, 2008.

Monteys, X. La habitación. Más allá de la sala de estar. Barcelona: G. Gili, 2014.

Parra, J. "Imágenes y metáforas del agua en el pensamiento de Le Corbusier". Valencia: ViA-arquitectura, $\mathrm{N}^{\circ}$ 10, 2001.

Quetglas, J. "Hacia Ronchamp” en: AA.VV. Le Corbusier, mensaje en una botella. Alicante: CTAA, 2011.

Rowe, C. Manierismo y arquitectura moderna y otros ensayos. Barcelona: Gustavo Gili, 1980.

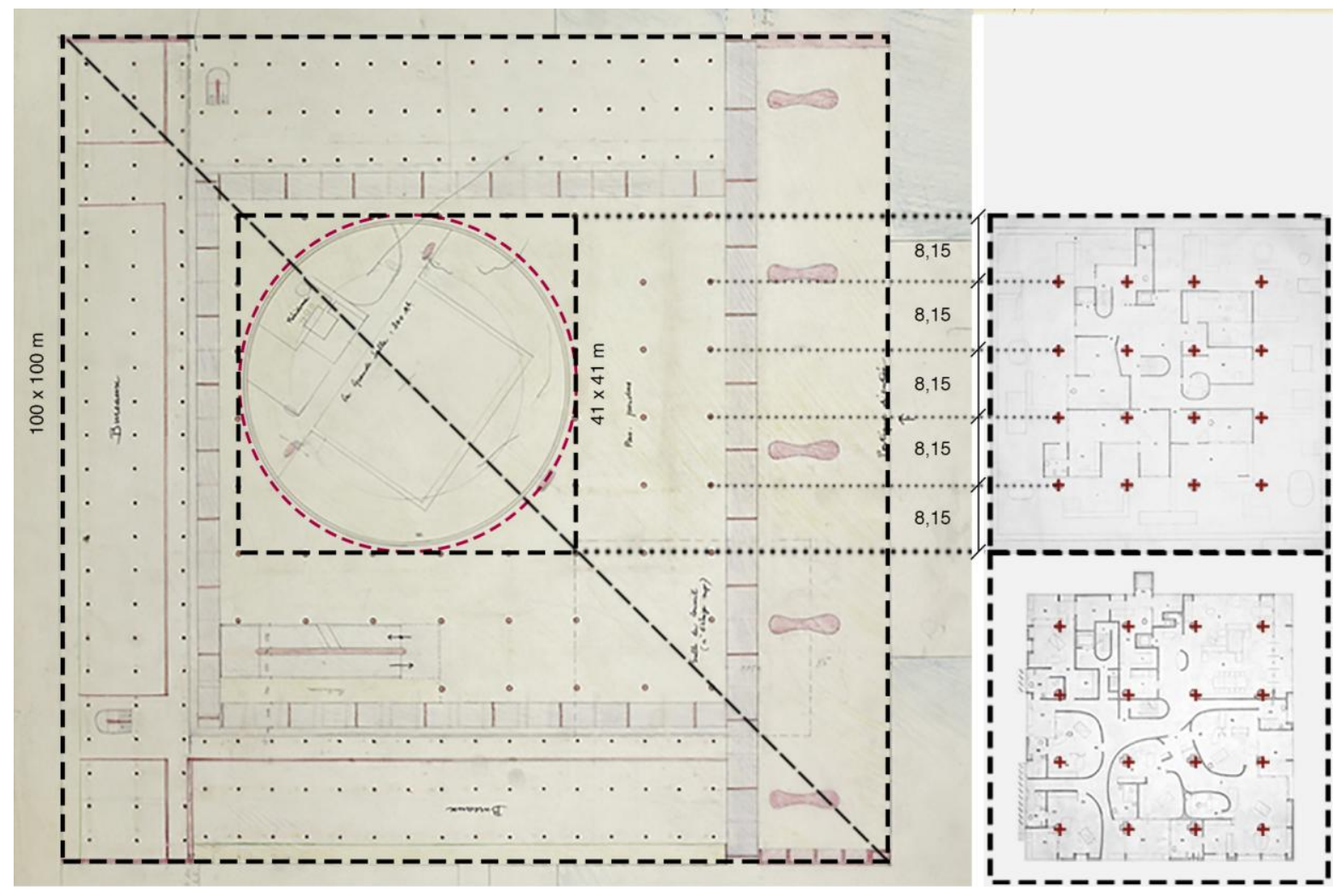

6. Capitolio de Chandigarh: planta baja del palacio de la Asamblea y dos plantas altas del palacio del Gobernador. 